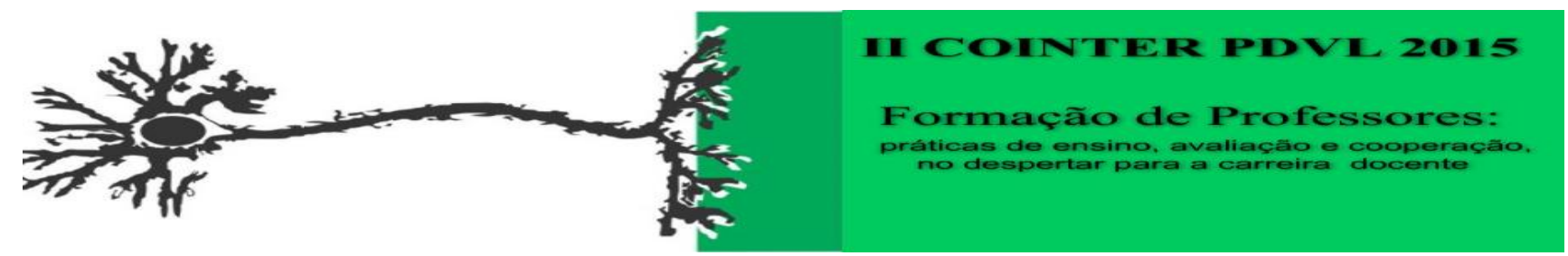

\title{
EXPERIMENTAÇÃO INVESTIGATIVA: UMA VISÃO ATRAVÉS DE PROFESSORES DO ENSINO MÉDIO
}

\author{
Apresentação: Pôster
}

Ana Paula Ferreira da Silva ${ }^{1}$; Rafaela Germania Barbosa de Araújoº ; Claúdio Henrique Alves Perdigão ${ }^{3}$; Kilma da Silva Lima Viana ${ }^{4}$

\section{Introdução}

A experimentação para o processo de ensino-aprendizagem é de fundamental importância para o ensino de Química, e essa é uma representação compartilhada entre muitos professores. Desse modo, a abordagem experimental dita tradicional por sua natureza de passividade por parte do discente traz limitações na exploração das habilidades cognitivas. O que justifica a busca por metodologias capazes de fomentar tais habilidades do aluno, tornando-o protagonista desse processo.

Atualmente, muitos trabalhos têm se direcionado para o envolvimento ativo do aluno no processo de construção de seu conhecimento. Mais especificamente, o ensino por investigação, (também denominado experimentação problematizadora), ganha um apreço diferencial valorizando a participação efetiva do estudante em situações como: resolução de problemáticas, possibilidade a predizer respostas, testar hipóteses, argumentar, discutir com os pares, habilidades cognitivas que favorecem a aplicação do conteúdo correlacionado. Logo, é essencial o professor conhecer metodologias que ressaltem a participação ativa do aluno, para que atribui em suas aulas tanto o caráter experimental, quanto o investigativo, valorizando o protagonismo do aluno.

\section{Fundamentação Teórica}

Ainda são muitos os docentes que lecionam, imaginando ser possível comprovar a teoria no laboratório. Uma visão de ciência externa, neutra, quantitativa, empírica gera no ensino e na

\footnotetext{
${ }^{1}$ Licenciatura em Química, IFPE, anapaulafesil@gmail.com

${ }^{2}$ Licenciatura em Química, IFPE rafaelagermania@hotmail.com

3 Mestre em Ensino de Ciências, IFPE, claudio.perdigao@vitoria.ifpe.edu.br

${ }^{4}$ Doutora em Ensino de Ciências (Física e Química), IFPE, kilma.viana@vitoria.ifpe.edu.br
} 
aprendizagem uma visão de sujeito isento/neutro, que reproduz de forma passiva o que lhe é apresentado. Na medida em que o professor encara a ciência com a visão 'do verdadeiro, do definitivo, do certo', o aluno, consequentemente, vai reproduzir tal visão, apresentando e interiorizando a falsa idéia de que há uma única resposta plausível para qualquer questão que lhe for proposta (AMARAL; SILVA, 2000).

Segundo Hodson (1994) o ensino experimental precisa envolver mais reflexão do que trabalho prático. Nenhuma atividade experimental assegura, por si só, a obtenção dos efeitos esperados no processo de ensino-aprendizagem. Dentre as dificuldades já assinaladas anteriormente, destaca-se também a maneira pouco reflexiva com que os professores elaboram seus planos de aula e fazem uso do trabalho prático.

Segundo Oliveira (2009), a importância da inclusão da atividade de experimentação está na caracterização de seu papel investigativo e de sua função pedagógica em auxiliar o aluno na compreensão dos fenômenos sobre os quais se referem os conceitos. No entanto, a atividade de experimentação, na maioria das vezes quando ocorre, tem o professor como ator principal aquele que realiza a atividade e cabendo ao aluno, durante a exposição do professor, e quando muito anotar as observações do fenômeno. Dessa forma, a atividade não vai além da simples demonstração ou comprovação de uma teoria estudada em sala de aula. A principal característica de uma atividade de experimentação é a investigação, a solução de problemas, que possibilita ao aluno agir ativamente, dialogando com seus colegas e o professor, formulando e discutindo suas ideias e hipóteses sobre o fenômeno que está sendo observado protagonizando o experimento e a construção de seu conhecimento.

Conforme Moreira (1983) a resolução de problemas que leva a uma investigação deve estar fundamentada na ação do aluno. Os alunos devem ter oportunidade de agir. Não se limitando a observação, deve ter características de um trabalho científico: deve haver a reflexão, discussão, explicação, relatos, o que dá ao seu trabalho características de uma investigação científica. Nesta perspectiva, o ensino por investigação torna-se contrário ao método científico descrito nos livros de ciências, como um método fechado, com sequência lógica e rígida, com o passo a passo a ser seguido dando a ideia de uma ciência definitiva, criada a partir e somente através da observação (AZEVEDO, 2004).

A promoção de um ensino mais interativo, dialógico e baseados em atividades capazes de persuadir os alunos a admitirem as explicações científicas para além dos discursos autoritários, 
prescritivos e dogmáticos torna o ensino por investigação uma importante estratégia para os professores utilizarem na sala de aula (MUNFORD, CASTRO E LIMA, 2007).

\section{Metodologia}

Este trabalho trata de um estudo exploratório realizado por um grupo de trabalho, no curso de Licenciatura em Química, ao nível de graduação, no Instituto Federal de Educação, Ciência e Tecnologia de Pernambuco (IFPE) - Campus Vitória de Santo Antão - fomentado pelo Programa Institucional de Bolsa de Incentivo à Docência, desenvolvido na Escola de Referência em Ensino Médio José Joaquim da Silva filho, no município de Vitória de Santo Antão.

A pesquisa apresenta as características de uma abordagem qualitativa, uma vez que se investigou as respostas do questionário semiestruturado realizado pelos três professores da escola. Levando em consideração suas percepções a cerca da experimentação, focalizando a abordagem investigativa. Foram realizadas seis perguntas aos professores, objetivando entender as perspectivas dos professores quanto à importância da experimentação no ensino de química e delimitar suas limitações, e investigar seus conhecimentos a cerca da abordagem investigativa, porém para garantir o anonimato de suas respostas, trataremos os docentes como P1, P2 e P3.

\section{Resultados e Discussões}

Em relação às perspectivas encontradas sobre o ensino de química em resposta a Pergunta 1. Como você avalia o ensino de Química? Todos os professores da pesquisa afirmaram a dificuldade encontrada para ministrar as aulas em laboratório, pois como a Química é uma disciplina que carrega essa característica da instrumentalidade, é de fundamental importância a aproximação do aluno a esse ambiente científico de cunho investigativo, salientaram a carência de reagentes e demais equipamentos essenciais para realização das aulas práticas. Além de ser ressaltada a natural repulsa dos alunos em decorrência ao tabu errôneo que a Química é uma disciplina monótona, que envolve muitos cálculos e memorização de conteúdos.

Iniciando os questionamentos sobre a experimentação, fez-se a Pergunta 2. Costuma aplicar aulas experimentais? Notou-se novamente a unanimidade positiva nas respostas, onde o P2 ressalta o uso de matérias de baixo custo, em decorrência dos materiais escassos ou alguns inexistentes do laboratório. Dentro da pergunta 2, ainda houve subdivisões, como com que frequência as aulas são ministradas, e se os docentes costumam notar diferenças significantes entre 
o ensino com e sem experimentos. Analisamos que o P2 afirma uma maior constância, efetuando uma prática experimental por semana, enquanto o P1 e P3 realizam em intervalos mensais. No ultimo quesito dessa pergunta, os três docentes justificaram que conseguem perceber a diferença que o ensino experimental atua sobre os alunos, pois as aulas tornam-se mais dinâmicas e motivadoras, favorecendo uma facilidade maior na aprendizagem dos alunos.

Já que as respostas foram positivas, quanto a significância das aulas, na resposta a Pergunta 3. Quais as principais dificuldades encontradas na elaboração de aulas experimentais? Percebemos que, em concordância a resposta da primeira pergunta o principal agravante que dificulta as aulas instrumentais, era a escassez principalmente de reagentes, além da precária estrutura física do laboratório, além do tempo para organizar esse tipo de aula.

A partir dessas próximas questões, foi focalizada a temática da abordagem investigativa, na Pergunta 4. Você já ouviu falar sobre experimentação investigativa? Ponderamos que um dos três professores não conhecia esse viés da experimentação $(\mathrm{P} 2)$. Todavia incorporamos à questão um tópico com o seguinte quesito: Como você acha que funciona esse tipo de experimentação? E através da observação do retorno da pergunta, constatamos que todos os professores tinham concepções corretas sobre o ensino experimental investigativo. Exemplificado na resposta do docente que havia marcado no mesmo questionamento que nunca ouviu falar sobre essa abordagem:

P2 - São experimentos que buscam resultados para alguns fenômenos a partir de atividades experimentais que ressaltam a investigação, supervisionada pelo professor.

Posteriormente para avaliar se suas concepções sobre experimentação investigativa e os sujeitos que podem executar a prática, foram realizados mais dois quesitos: Pergunta 5. Você acha que um aluno durante as aulas experimentais pode ele mesmo executar o experimento? Unanimemente, todos os professores responderam que sim, porém com supervisão do professor, já que é muito perigoso alunos manusearem alguns compostos como reagentes que podem causar corrosão se derrubados na pele por exemplo.

E por fim a Pergunta 6. Qual deve ser o papel do professor durante uma aula experimental? Obtivemos novamente uma sincronia entre as respostas dos três professores, justificaram suas respostas explicando que o principal papel de um professor é a coordenação, mediação e supervisão do experimento. 


\section{Conclusões}

Através da análise dos questionários, foi possível depreender, pelos relatos dos professores, há barreias que permeiam e dificultam o ensino experimental da Química, tais como: precariedade física dos laboratórios, escassez de materiais, falta de tempo para elaboração desse tipo de aula, que convergem para aulas eventuais, ou com o uso de materiais alternativos.

Quanto às concepções sobre a experimentação, observamos que todos compreendem a fundamental importância desse tipo de abordagem, por ser cativante, estimulante e motivadora, já que confere as aulas um aspecto lúdico e faz com que os alunos percebam que a Química não é uma Ciência chata e monótona, restrita a memorização.

Concluímos, sobretudo, que embora seja uma prática pouco utilizada pelos professores da Educação Pública os professores têm o conhecimento sobre o que se trata o ensino por investigação, e possuem alguns traços que podemos perceber em suas respostas, como o papel do docente de mediar à experimentação dos alunos, e estes podendo também executar experimentos, e investigar fenômenos.

\section{Referências}

AMARAL, L.O.F.; SILVA, A.C. Trabalho Prático: Concepções de Professores sobre as Aulas Experimentais nas Disciplinas de Química Geral. Cadernos de Avaliação, Belo Horizonte, v.1, n.3, p. 130-140. 2000.

AZEVEDO, M. C. P. S. Ensino por investigação: problematizado as atividades em sala de aula. In: CARVALHO, A. M. P. (Org.). Ensino de Ciências: unindo a pesquisa e a prática. São Paulo: Pioneira Thomson Learning, 2004. p. 19-33.

HODSON, D. Hacia um Enfoque más Crítico del Trabajo de Laboratório. Enseñanza de lãs Ciências, Barcelona, v. 12, n.3, p. 299-313. 1994.

MOREIRA, M. A. Uma abordagem cognitivista ao ensino de física. Porto Alegre: Editora da Universidade, 1983.

MUNFORD. D.; CASTRO e LIMA, M. E. C. Ensinar Ciência por investigação: em que estamos de acordo? Ensaio - Pesquisa em Educação em Ciência, Belo Horizonte, v. 9, n. 1, p. 72-89, 2007.

OLIVEIRA, N. Atividades de Experimentação Investigativas Lúdicas no Ensino de Química: Um estudo de caso. Tese (doutorado em Química) - Universidade Federal de Goiás, Goiânia - GO, 147 p. 2009 
